\title{
Estrus traits derived from activity measurements are heritable and closely related to the time from calving to first insemination
}

\author{
Ahmed Ismael, ${ }^{\dagger} \dagger^{1}$ Erling Strandberg, $\dagger$ Morten Kargo, ${ }^{*} \ddagger$ Anders Fogh,$\ddagger$ and Peter Løvendahl ${ }^{*}$ \\ *Department of Molecular Biology and Genetics, Aarhus University, PO Box 50, DK-8830 Tjele, Denmark \\ †Department of Animal Breeding and Genetics, Swedish University of Agricultural Sciences, PO Box 7023, SE-750 07 Uppsala, Sweden \\ ¥Knowledge Center for Agriculture, DK-8200 Aarhus N, Skejby, Denmark
}

\begin{abstract}
The aim of this study was to estimate genetic parameters for estrus-related traits that could improve selection for increased fertility due to improved ability of the cow to return to cycling and go into heat after calving. We compared the time from calving to first insemination (CFI) to 3 physical activity traits: the interval from calving to first high activity (CFHA), estrus duration (ED), and estrus strength (ES). We calculated CFI based on data from commercial Holstein herds that included the insemination dates for 11,363 cows. The CFHA, ED, and ES traits were derived from electronic activity tags for 3,533 Holstein cows. Estimates of heritability were 0.07 for CFI, 0.16 for CFHA, 0.02 for ED, and 0.05 for ES. We found a strong genetic correlation between CFI and CFHA (0.96). Genetic correlations between ED and CFI and CFHA were -0.37 and -0.68 , respectively. Genetic correlations between ES and CFI and CFHA were -0.50 and -0.58 , respectively. The heritability of CFHA and its strong genetic correlation with CFI suggest that including CFHA in the genetic evaluation of female cow fertility could improve the effectiveness of selection, because CFHA reflects the ability to return to cyclicity and go into heat after calving.
\end{abstract}

Key words: activity tag, heritability, estrus, fertility

\section{INTRODUCTION}

Fertility is one of the most important traits in breeding dairy cows. Miglior et al. (2005) reported that selection indices worldwide have changed the previous focus on yield to a more balanced breeding approach that includes longevity, udder health, and fertility. Fertility has a significant effect on the overall profitability of dairy cattle production, because improving fertility reduces the number of inseminations and veterinary

\footnotetext{
Received October 6, 2014.

Accepted January 20, 2015

${ }^{1}$ Corresponding author: ahmed.ismael@mbg.au.dk or ahmedismael sayed@gmail.com
}

treatments required, shortens the calving intervals, and lowers the rates of involuntary culling (Sewalem et al., 2008).

Female fertility is a combination of many underlying traits. The traits usually used in genetic evaluations of female fertility reflect 2 aspects of fertility. The first is the ability of the cow to return to cycling and to go into heat after calving (i.e., the time from calving to first insemination and the heat strength). The second is the ability of the cow to conceive following insemination and become pregnant (i.e., the time between the first and last inseminations, the number of inseminations per conception, and the nonreturn rate within $56 \mathrm{~d}$ after first service). Some traits represent a combination of these abilities (e.g., calving interval and days open; Jorjani, 2006, 2007).

Generally, fertility traits have low heritability (0.01 to 0.10; Hou et al., 2009; Sun et al., 2009, 2010). This may be because many fertility traits are categorical in nature (e.g., nonreturn rate and number of inseminations per conception), but even those measured on a continuous scale are heavily influenced by management decisions (e.g., voluntary waiting period) and often include censored records (e.g., missing records for cows that did not cycle or conceive within the observation period; Sun et al., 2009). This gives rise to large unexplained variation that can mask genetic effects.

The time from calving to first insemination (CFI) is a measure of the ability of a cow to return to cyclic estrus after calving and may be regarded as an indirect measure of the time from calving to first ovulation (Petersson et al., 2007). Early onset of estrus cyclicity with clear estrus behavior increases the chance of a successful insemination after calving, both because it shortens the time from calving to estrus and also because it increases the conception rate at estrus, and thereby reduces the number of services per conception (Darwash et al., 1997a). However, CFI is influenced by management strategies; for example, by imposing a voluntary waiting period (Löf et al., 2012) or inseminating high-yielding cows later than low-yielding cows (Andersen-Ranberg et al., 2005). Consequently, 
estimated CFI heritability is usually low, ranging from 0.03 to 0.13 (Roxström et al., 2001a; Andersen-Ranberg et al., 2005; Sun et al., 2009).

To overcome the low heritability of CFI, objective measures have been introduced that directly reflect physiological and behavioral changes related to estrus. For instance, the interval from calving to commencement of luteal activity (C-LA), which occurs 4 to 5 $\mathrm{d}$ after first ovulation, is a more objective measure of the return to cyclicity than CFI (Petersson et al., 2006, 2007). This trait can be determined by evaluating progesterone profiles, and its heritability is estimated to be 0.16 to 0.30 , which is considerably higher than heritability estimates for CFI (Veerkamp et al., 2000; Royal et al., 2002a; Petersson et al., 2007). The drawback of C-LA is that it is based on frequent measuring of milk progesterone (Petersson et al., 2007), which is both costly and logistically challenging: milk samples in the regular milk recording are usually taken infrequently (once a month). Other indirect methods for detecting a return to cyclicity include electronic pedometers or activity tags that measure behavioral changes that occur due to the increase of follicular estradiol in blood to indicate estrus in dairy cows (Wiltbank et al., 2006). In an experimental study on 515 cows by Løvendahl and Chagunda (2009), heritabilities of 0.12 to 0.18 were obtained for the time from calving to the first sign of high activity (CFHA).

Therefore, this study aimed to estimate genetic parameters for CFHA, estrus duration (ED), and estrus strength (ES), based on activity measurements from cows in commercial herds, and to compare these with parameter estimates for CFI.

\section{MATERIALS AND METHODS}

\section{Design and Data}

The CFI and physical activity traits were based on raw data measured in the Danish Holstein population from January 2010 to June 2012. The cows were housed among 68 commercial herds. The pedigree was built using a sire-dam structure and tracing back as many generations as possible in the Nordic Cattle database (NAV, Skejby, Denmark). The total pedigree file included 87,916 animals. Physical activity data were collected from electronic activity tags fitted on cow neckbands (Lely Qwes-H or Qwes-HR, Lely Industries BV, Maassluis, the Netherlands). Cow activity was measured as the number of electronic impulses per 2-h bin triggered by changes in acceleration due to head and neck movements. Insemination data were used to calculate CFI, which was restricted to 20 and 200 DIM (Banos et al., 2004). Only records from cows in first to third parities were included in the analysis. When a cow had data from more than one parity, only the earliest parity and the corresponding physical activity records were included in the analysis.

For comparisons between CFHA and CFI as the 2 methods of recording first estrus events, we calculated the time from calving to first estrus in a subset of cows that had both the traditional AI information and data from activity measurements. To be eligible for inclusion in the analysis, the activity recording had to include the period from 15 to $155 \mathrm{~d}$ postpartum. Within this period, every cow had to have records for at least 45 consecutive days of activity, because different farms had different start times in the physical activity recording.

After editing, the final data set for CFI contained records from 11,363 cows. Of these cows, 3,533 cows also had phenotypic records of CFHA and multiple records for ED and ES in the same parities.

\section{Algorithm for Defining Estrus Activity Traits}

Physical activity data were processed with an algorithm designed to detect changes in cow activity. The main reason for developing an algorithm to detect estrus was that the commercial algorithms were not openly available. Raw data was filtered to remove duplicated and missing records. Each cow's activity was standardized to the herd average by calculating the activity ratio $\left(A R_{t}\right)$, which is the activity count at time $(t)$ of day divided by the mean activity of the herd at the same time. This standardization adjusts the activity to account for diurnal rhythms and day-to-day changes. For each cow, the baseline value was obtained with an exponentially smoothed time series of the $A R_{t}$, calculated as $S_{t}=(1-\alpha) S_{t-1}+\alpha A R_{t}$, where $\alpha$ was the smoothing constant for the data, which specified the relative weight of new information, and $S_{t}$ was the smoothed ratio at time $t$. An estrus-related change in activity was defined as a deviation in $A R_{t}$ that exceeded a set threshold (T) above the $S_{t}$ (Figure 1). These deviations typically preceded the onset of a high activity episode. A high activity episode was defined as at least 3 consecutive deviations that exceeded the threshold; thus, we censored high activity episodes shorter than $6 \mathrm{~h}$, which resulted in a minimum ED of $6 \mathrm{~h}$ to avoid short interval episodes that could constitute false positives. An episode ended when 2 consecutive deviations were below the threshold.

Heritability of CFHA was estimated in the full data set. This estimate served as a criterion for selecting the best settings for the smoothing constant $(\alpha)$ and the threshold value $(\mathrm{T})$ parameters in the heat detection algorithm. The performance of the algorithm was validated with 548 cows that had undergone successful AI, 
ISMAEL ET AL.

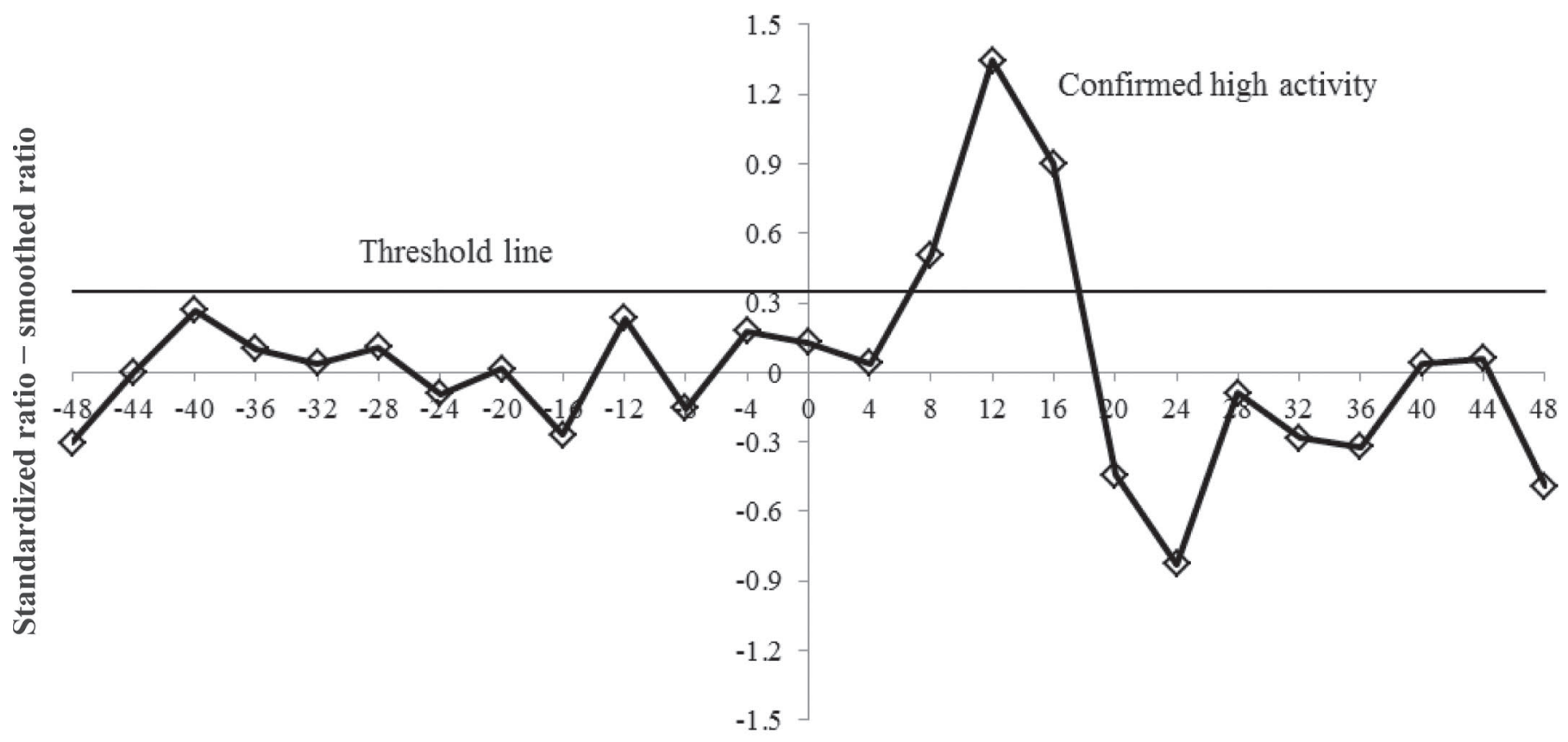

Time (h)

Figure 1. Deviations between standardized activity $\left(A R_{t}\right)$ and the smoothed activity ratio $\left(S_{t}\right)$ for a representative cow; time frame is $48 \mathrm{~h}$ before and $48 \mathrm{~h}$ after the start of the high activity episode. The threshold of high activity was 0.35 .

based on birth of a calf or a confirmed pregnancy. We analyzed activity data from $14 \mathrm{~d}$ before to $14 \mathrm{~d}$ after AI. This period was divided into 3 periods: early $(-14$ $\mathrm{d}$ to $-2 \mathrm{~d})$, on time $(-1 \mathrm{~d}$ to the AI day), and late $(1 \mathrm{~d}$ to $14 \mathrm{~d}$ ). Then, we calculated the sensitivity, detection rate, and daily error rate for the algorithm as follows: sensitivity of heat detection $=100 \times$ (number of cows detected by the algorithm/total number of cows in estrus) (de Mol and Woldt, 2001); detection rate $=100 \times$ (the number of high activity episodes detected during the observation time/total number of cows in estrus) (Løvendahl and Chagunda, 2010); and daily error rate $=100 \times$ (number of early episodes + number of late episodes)/(number of days "early" + "late") (Hogeveen et al., 2010).

Three estrus activity traits were defined as follows: (1) CFHA; (2) ED, defined as the interval (h) between the start and end of each high activity episode; and (3) ES, defined as the mean of the 2 highest deviation values during the high activity episode. The ES was $\log$-transformed $(l n)$, and 1.0 was added to this value before statistical analyses.

\section{Statistical Analysis}

The HPMIXED procedure in the SAS package (ver. 9.3; SAS Institute Inc., Cary, NC) was used to test for fixed effects in the model. Genetic analysis was performed with the average information REML, in the DMU package (Madsen and Jensen, 2010). Univariate analysis was performed to estimate heritability, based on variance components, for each trait separately. Bivariate analyses were performed to estimate genetic correlations between the traits.

To analyze CFHA and CFI, the following animal model was used:

$$
y_{i j k l}=y m_{i}+p_{j}+h_{k}+a_{l}+e_{i j k l}
$$

where $y_{i j k l}$ is the observation of the traits CFHA and CFI; $y m_{i}$ is the fixed effect of the year-month combination of estrus episode ( $i=1$ to 25), for CFHA, or the fixed effect of the year-month of insemination $(i=1$ to $29)$, for CFI; $p_{j}$ is the fixed effect of the parity $(j=1$ to $3) ; h_{k}$ is the fixed effect of herd ( $k=1$ to 68$) ; a_{l}$ is the random genetic effect $\sim N D\left(0, \mathbf{A} \sigma_{a}^{2}\right)$, where $\sigma_{a}^{2}$ is the additive genetic variance and $\mathbf{A}$ is the additive relationship matrix ( $l=1$ to 3,533 for CFHA) and ( $l=1$ to 11363 for $\mathrm{CFI})$; and $e_{i j k l}$ is the random residual $\sim \operatorname{IND}\left(0, \sigma_{e}^{2}\right)$.

To analyze ED and ES, the following animal model was used:

$$
y_{i j k l m}=y m_{i}+p_{j}+h_{k}+a_{l}+p e_{m}+e_{i j k l m},
$$


Table 1. Number of cows and records, and the means, standard deviations, and minimum and maximum values for activity-based estrus traits

\begin{tabular}{lcccccc}
\hline Trait $^{1}$ & No. of cows & No. of records & Mean & SD & Minimum & Maximum \\
\hline CFI (d) & 11,363 & 11,363 & 75.3 & 32.0 & 20.0 & 200.0 \\
CFHA (d) & 3,533 & 3,533 & 49.5 & 27.0 & 5.0 & 153.0 \\
ED $(\mathrm{h})$ & 3,533 & 12,127 & 8.5 & 2.9 & 6.0 & 22.0 \\
ES $\left[\ln \left(A R_{t}-S_{t}\right)+1\right]$ & 3,533 & 12,127 & 1.04 & 0.45 & 0.001 & 2.8 \\
\hline
\end{tabular}

${ }^{1} \mathrm{CFI}=$ interval from calving to first insemination; $\mathrm{CFHA}=$ interval from calving to first high activity; $\mathrm{ED}=$ estrus duration; ES = estrus strength (based on the log-transformed mean of the 2 highest deviations between standardized activity $\left(A R_{t}\right)$ and the smoothed activity ratio $\left(S_{t}\right)$ during the estrus episode; see Figure 1).

where $y_{i j k l m}$ is the observation of the traits ED and ES; $y m_{i}$ is the fixed effect of the year-month combination of heat episode $(i=1$ to 28$) ; p_{j}$ is the fixed effect of the parity $(j=1$ to 3$) ; h_{k}$ is the fixed effect of herd $(k=1$ to 68$) ; a_{l}$ is the random genetic effect $\sim N D\left(0, \mathbf{A} \sigma_{a}^{2}\right)$, where $\sigma_{a}^{2}$ is the additive genetic variance and $\mathbf{A}$ is the additive relationship matrix $(l=1$ to 3,533$) ; p e_{m}$ is the random permanent environmental effect of animal $l \sim \operatorname{IND}\left(0, \sigma_{p e}^{2}\right) ;$ and $e_{i j k l m}$ is the random residual $\sim \operatorname{IND}\left(0, \sigma_{e}^{2}\right)$.

We obtained the standard errors of heritabilities and genetic correlations from standard errors of covariance components using a Taylor series expansion (Madsen and Jensen, 2010).

\section{RESULTS AND DISCUSSION}

\section{Heat Detection Algorithm}

We developed an estrus detection algorithm to replace that used by the commercial manufacturer of the activity tags used in this study. The performance of the algorithm was similar to previously reported and validated algorithms with respect to detection and error rates (At-Taras and Spahr, 2001; Roelofs et al., 2005; Løvendahl and Chagunda, 2010). To our knowledge, validation results for commercial algorithms are not readily available; therefore, a comparison was not possible. However, the obtained results were deemed satisfactory for the purpose of this study.

The highest heritability estimate for CFHA in the full activity data set was 0.16 , obtained with $\alpha=0.10$ and a threshold $t=0.35$. The selected settings yielded a detection rate of $87 \%$, a sensitivity of $83 \%$, and a daily error rate of $0.9 \%$. At-Taras and Spahr (2001) and Roelofs et al. (2005) found a similar detection rate (87\%) for Holstein cows using activity tags and pedometers for estrus detection. Løvendahl and Chagunda (2010) reported a similar daily error rate (0.93\%) using activity tags for estrus detection, whereas Maatje et al. (1997) reported a higher error rate of $32 \%$ using pedometers for estrus detection.

\section{Descriptive Statistics}

Descriptive statistics of the traits are shown in Table 1. The average CFHA was $49.5 \mathrm{~d}$ and the mean ED was $8.5 \mathrm{~h}$. These estimates are slightly higher than those obtained by Løvendahl and Chagunda (2010), who reported a mean CFHA of $44 \mathrm{~d}$ and a mean ED of $8.1 \mathrm{~h}$. However, an estimated duration of $10.0 \mathrm{~h}$ was reported by Roelofs et al. (2005), who used pedometers with 2 -h recording bins, and another estimate of $11.8 \mathrm{~h}$, which was based on visual observation at 3 -h intervals. The different results may be related to activity tags from different manufacturers, which may have used different recording intensities (1- or 2-h time bins) or different detection algorithms.

The CFI distribution was bimodal, with a clear peak at $60 \mathrm{~d}$ and a tendency to a peak at $80 \mathrm{~d}$ (Figure 2). The CFHA distribution showed a similar pattern, but only one main peak was observed at $40 \mathrm{~d}$. These results suggest that unobserved heats may have occurred before AI. The frequency distribution of ED (Figure 3) showed that most estrus periods lasted $6 \mathrm{~h}(39 \%)$, which was the shortest possible measurement in our study. The values of ES were distributed almost normally (Figure 4), with a mean of 1.04, in log-transformed units (Table 1). For the algorithm settings used, this mean ES was equivalent to a 2.5 -fold increase in individual cow activity. This finding is consistent with other studies (Firk et al., 2002; Løvendahl and Chagunda, 2009), who reported that estrus caused a 3 -fold increase in individual cow activity. The increase in physical activity was previously explained by Aungier et al. (2012) as being an effect of increased follicular estradiol production. Conversely, lower blood estradiol concentrations on the day of estrus were associated with a decrease of duration and intensity of behavioral signs of estrus, including both physical and mounting activity (Wiltbank et al., 2006). The increase of follicular estradiol concentration in blood at the day of estrus from 6.8 to $8.6 \mathrm{pg} / \mathrm{mL}$ was associated with an increase in estrus duration from 7 to $11.9 \mathrm{~h}$ and an increased average standing activity from 6.5 to 9.8 events (Lopez et al., 2004). These findings 


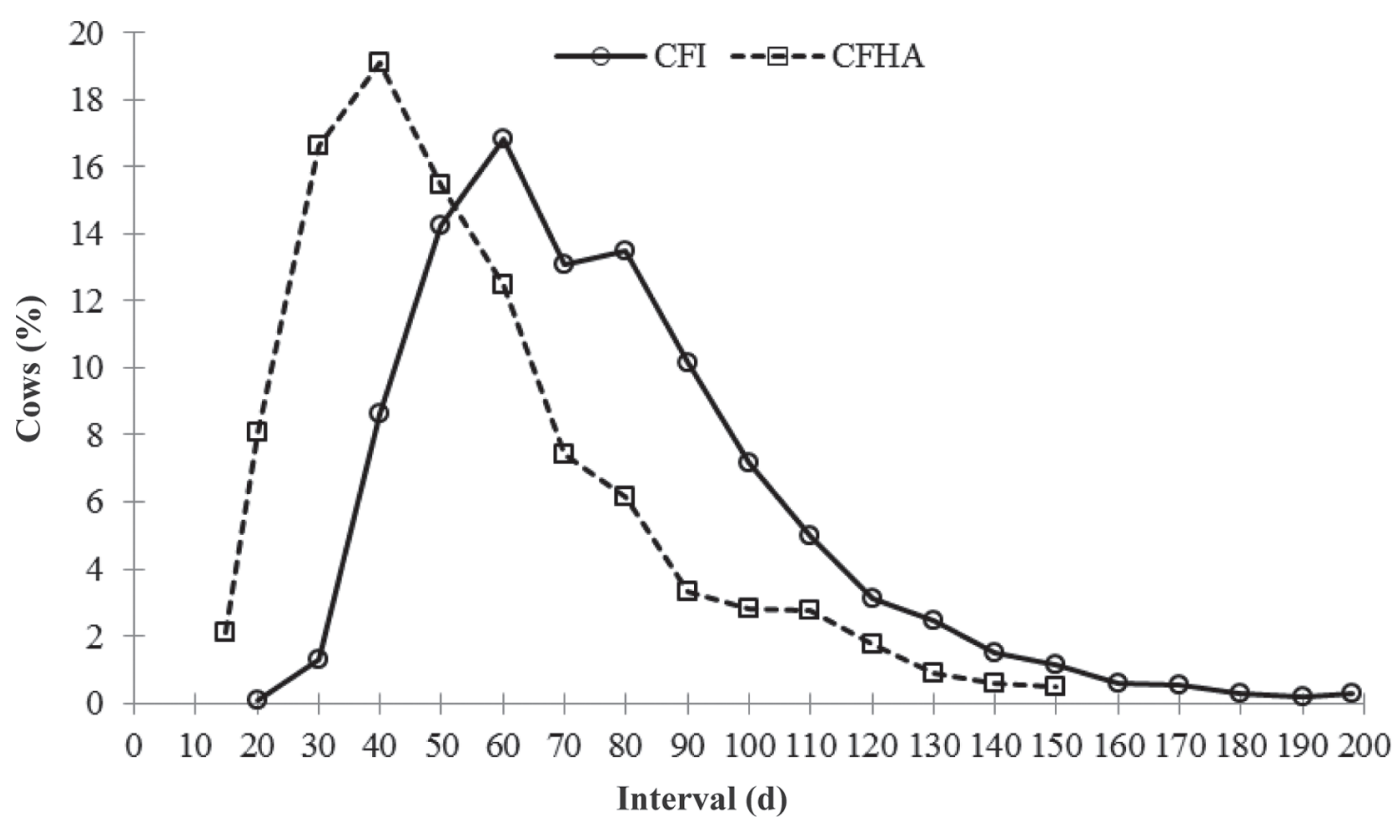

Figure 2. Distribution of the time intervals from calving to first high activity (CFHA) and the time intervals from calving to first insemination (CFI). The CFHA (dashed line) represents percentages from 3,533 dairy cows; the CFI (solid line) represents percentages from 11,363 cows.

support the hypothesis that behavioral expression of estrus is related to its endocrine regulation.

\section{Heritability Estimates}

The genetic parameters estimated for each trait are shown in Table 2. The heritability estimate for CFHA was moderate (0.16) but substantially higher than the heritability for CFI (0.07). Previous estimates of heritability for CFI ranged from 0.03 to 0.10 (Roxström et al., 2001a; Andersen-Ranberg et al., 2005; Sun et al., 2009). The heritability estimate for CFHA was consistent with heritability estimates reported by Løvendahl

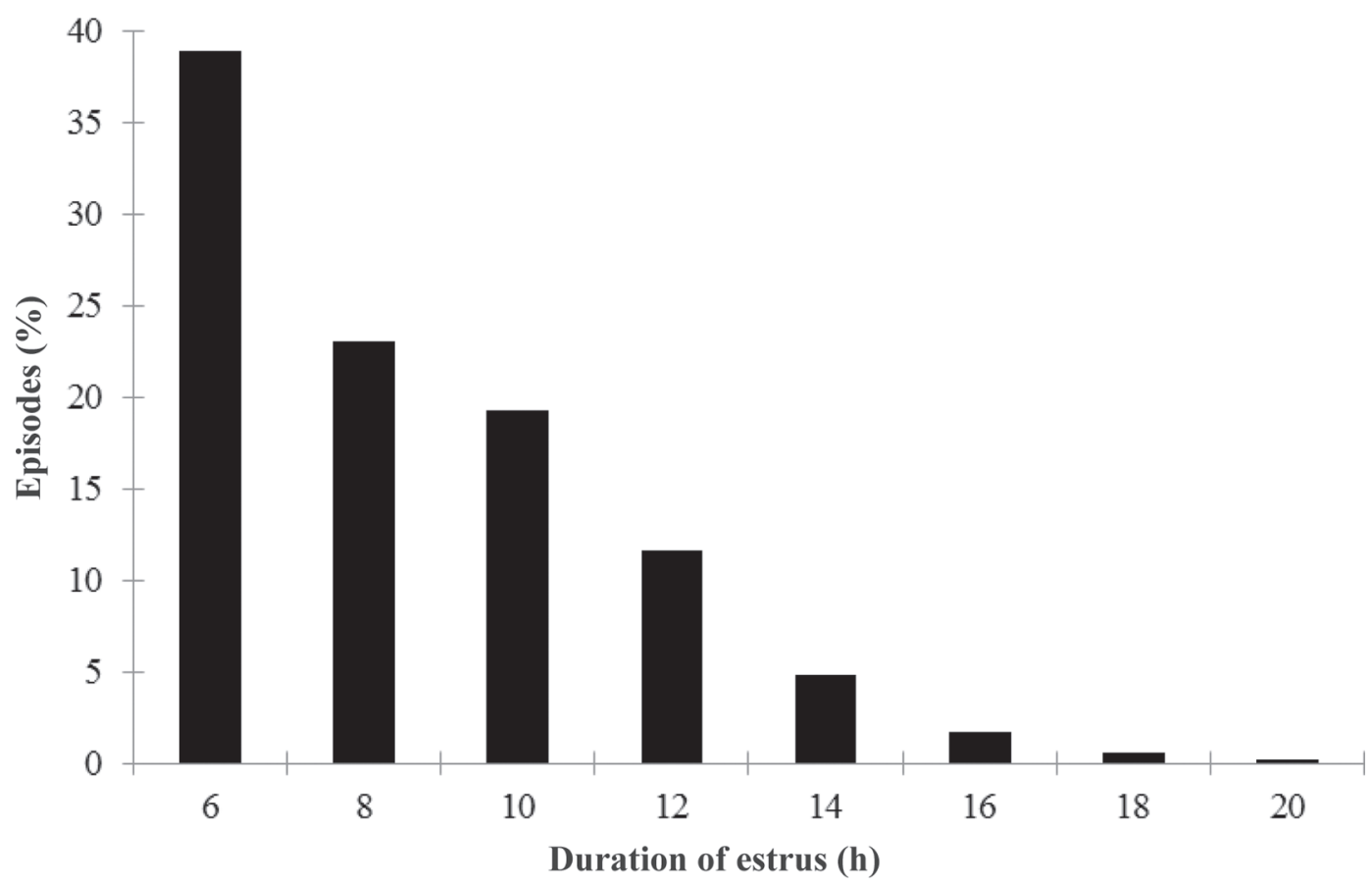

Figure 3. Distribution of estrus episode durations. The distribution represents percentages from 12,127 high activity episodes detected in 3,533 dairy cows. 


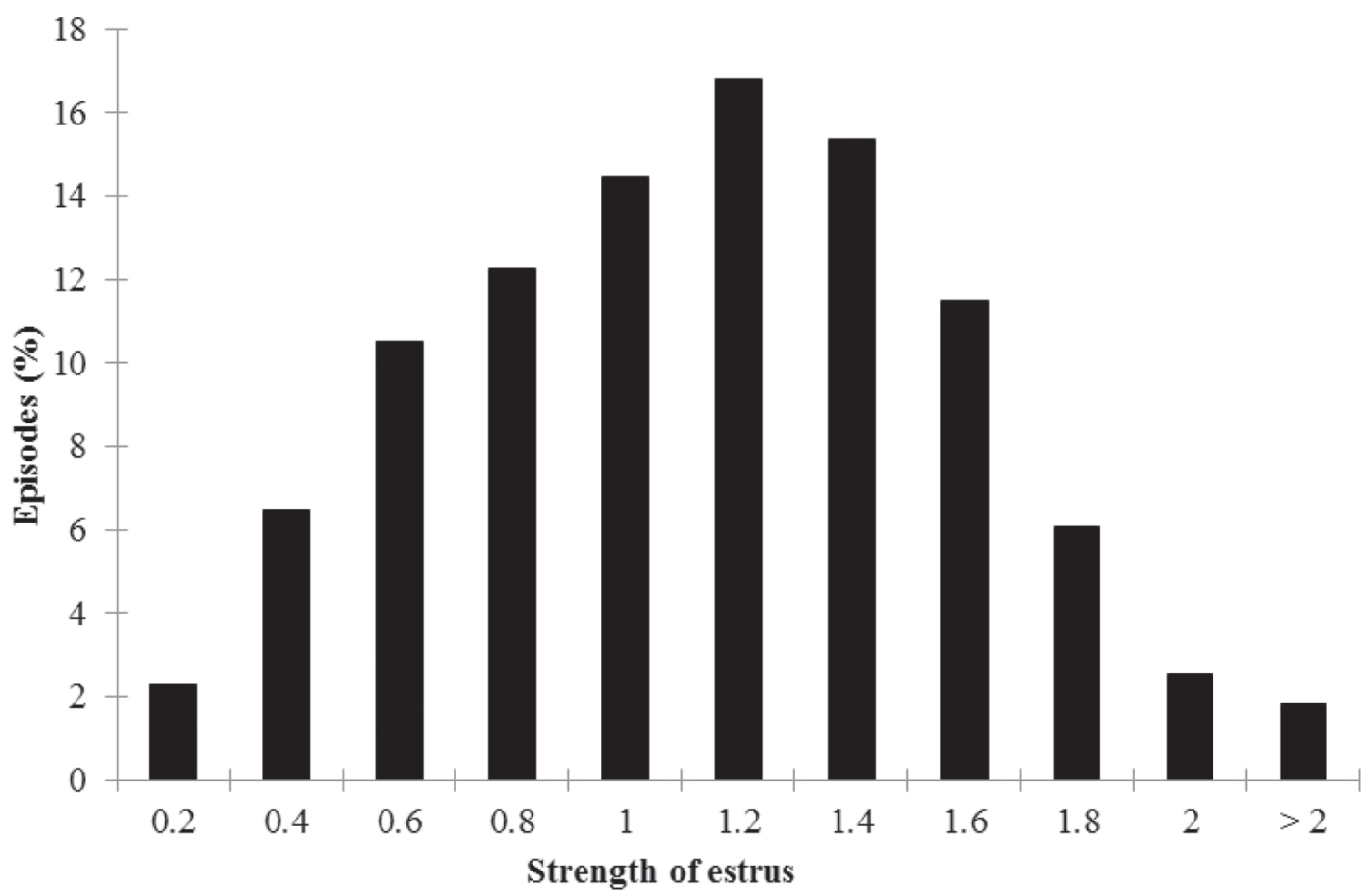

Figure 4. Distribution of the estrus episode strengths. The distribution represents percentages from 12,127 high activity episodes detected in 3,533 dairy cows.

and Chagunda (2009), which ranged from 0.12 to 0.18 . Previous experimental studies that used progesterone measurements in milk to detect the onset of estrus cyclicity after calving C-LA, obtained heritability estimates of 0.17 to 0.30 (Darwash et al., 1997b; Royal et al., 2002a; Petersson et al., 2007). Jointly, these and our results indicate that objective measures are valuable in detecting genetic variation in estrus traits.

The ED and ES exhibited low heritability estimates (0.02 to 0.05). Other estimates of heritability for ED and ES were also in the lower range, between 0.02 and 0.08 (Løvendahl and Chagunda, 2009). These estimates were only slightly larger than those found by Roxström et al. (2001b), who measured estrus intensity by evaluating visual signs of estrus and found heritability estimates between 0.01 and 0.03 . Hence, the ED and ES traits were clearly less heritable than the CFHA interval trait.

\section{Genetic and Phenotypic Correlations}

Genetic and phenotypic correlations are shown in Table 3. The genetic correlation between CFI and CFHA was positive and strong (0.96), which indicates that these traits measure the same aspect of reproductive performance in cows. Royal et al. (2003) reported a genetic correlation of 0.53 between CFI and C-LA. Furthermore, they found genetic correlations between a long C-LA and a long calving interval (0.39) and between C-LA and a high number of inseminations per

Table 2. Permanent environmental variance $\left(\sigma_{p e}^{2}\right)$, additive genetic variance $\left(\sigma_{a}^{2}\right)$, residual variance $\left(\sigma_{e}^{2}\right)$, heritability ${ }^{1}\left(h^{2}\right)$, and standard error of the heritability (SE) for activity-based estrus traits

\begin{tabular}{lccccc}
\hline Trait $^{2}$ & $\sigma_{p e}^{2}$ & $\sigma_{a}^{2}$ & $\sigma_{e}^{2}$ & $h^{2}$ & SE \\
\hline CFI & - & 65 & 814.7 & 0.07 & 0.02 \\
CFHA & - & 109.6 & 571.6 & 0.16 & 0.04 \\
ED & 1.06 & 0.18 & 6.8 & 0.02 & 0.01 \\
ES & 0.03 & 0.01 & 0.16 & 0.05 & 0.01 \\
\hline
\end{tabular}

${ }^{1}$ Where $h^{2}=\sigma_{a}^{2} /\left(\sigma_{p e}^{2}+\sigma_{a}^{2}+\sigma_{e}^{2}\right)$.

${ }^{2} \mathrm{CFI}=$ interval from calving to first insemination; $\mathrm{CFHA}=$ interval from calving to first high activity; $\mathrm{ED}=$ estrus duration; ES = estrus strength. 
Table 3. Genetic correlations (below diagonal; SE in parentheses) and phenotypic correlations (above diagonal) for activity-based estrus traits

\begin{tabular}{lrccr}
\hline Trait $^{1}$ & CFI & CFHA & ED & \multicolumn{1}{c}{ ES } \\
\hline CFI & & 0.38 & -0.10 & -0.16 \\
CFHA & $0.96(0.05)$ & & 0.03 & 0.02 \\
ED & $-0.38(0.27)$ & $-0.68(0.30)$ & & 0.44 \\
ES & $-0.50(0.22)$ & $-0.58(0.26)$ & $0.85(0.15)$ & \\
\hline
\end{tabular}

${ }^{1} \mathrm{CFI}=$ interval from calving to first insemination; $\mathrm{CFHA}=$ interval from calving to first high activity; $\mathrm{ED}=$ estrus duration; $\mathrm{ES}=$ estrus strength.

conception (0.05; Royal et al., 2002b, 2003), indicating that selection for a shorter interval from calving to estrus would benefit overall fertility.

Genetic correlations between CFHA and ED or ES were negative $(-0.68$ to -0.58$)$ and stronger than those found between CFI and ED or ES $(-0.38$ to -0.50$)$. These correlations indicate that cows with a delayed first estrus or insemination also have a weak, short estrus. Given these consistent results, it was not surprising that the genetic correlation between ED and ES was strong (0.85). Thus, cows with strong estrus signs also have a long estrus. The relationship between estrus intensity measured with visual scoring and that measured with traditional fertility measures shows that cows with genetically higher heat intensities have shorter CFI (genetic correlation of -0.36 ; Roxström et al., 2001b; E. Strandberg, unpublished data). Furthermore, cows with genetic backgrounds that confer high heat intensity also have fewer inseminations per conception, a shorter interval from first to last inseminations, and a shorter interval from calving to last insemination (genetic correlations: $-0.14,-0.27$, and -0.38 , respectively).

One explanation for the finding that ED and ES were more highly genetically correlated to CFHA than to CFI might be that CFHA was measured more precisely and was less influenced by farmers' decisions or interventions. Thus, the CFHA correlation reflects the underlying biological relationship better than the CFI correlation. Another potential reason could be that CFHA, ED, and ES were based on the same activity measurements. However, this explanation seems less likely, because the phenotypic and residual correlations between CFHA and these traits were low.

Our findings that CFHA had a higher heritability than CFI and that CFHA showed a strong genetic correlation with CFI imply that including CFHA, in addition to CFI, in the selection criteria might increase the genetic gain for the "return to cyclicity" trait. When we assume that CFI is the breeding goal trait and assume 100 daughters per sire, the accuracy of selection based only on CFI is 0.8 (applying selection index theory). If
$25 \%$ of the daughters also have information on CFHA, accuracy would increase to 0.85 (a $6.0 \%$ increase), which would translate into a larger genetic gain for CFI, when all else remains equal. In the latter case, the maximum possible accuracy (assuming all daughters had information on CFHA) would be 0.9 , representing a $13 \%$ increase.

Phenotypic correlations were found to be consistently smaller than their genetic counterparts. The strongest correlations were those between CFI and CFHA and between ED and ES (0.38 and 0.44, respectively). Therefore, CFI increased with increasing CFHA, and ED increased with increasing ES. The phenotypic correlations between CFI and ED and between CFI and ES were found to be weakly negative; in contrast, the corresponding correlations with CFHA were weakly positive. It was previously shown that at the phenotypic level, a favorable relationship between an early onset of estrus cyclicity and other fertility traits means that cows with shorter intervals from calving to estrus cyclicity have shorter CFI, shorter intervals from calving to conception, higher conception rates, and fewer inseminations per conception (Darwash et al., 1997a). Furthermore, Stevenson et al. (1983) reported that the early onset of estrus and stronger estrus expression resulted in an overall improvement of cow fertility.

The results of this study have important practical implications. First, incorporating the new traits into the breeding program requires collection and storage of activity data in a common database. This practice may cause little disruption because activity tags are currently available in many herds. Second, in addition to measuring CFHA, activity tags can also measure other traits (e.g., ES and ED). These traits are not routinely measured in most current breeding programs, but they could be useful for improving our ability to detect cows displaying estrus behavior.

\section{CONCLUSIONS}

This study used physical activity measurements from commercial herd data to develop 3 estrus activity traits: CFHA, ED, and ES. We showed that these activitybased traits are heritable and that CFHA is closely correlated with the traditional fertility trait CFI. The heritability of CFHA was higher than that of CFI, and a strong genetic correlation was found between these 2 traits. Therefore, including CFHA in the selection criteria, in addition to CFI, would increase the genetic drive for a rapid return to cyclicity, which would also have a positive effect on overall cow fertility. Furthermore, selection for ED and ES may improve heat detection, due to a longer display period and stronger activity peaks. 


\section{ACKNOWLEDGMENTS}

This study was conducted as part of the project "Nordic research network on animal genetic resources in the adaptation to climate change" funded by the AnGRNordic NET (NordGen, Nordic Council of Ministers, Ås, Norway). The authors acknowledge the Knowledge Center for Agriculture (Skejby, Denmark) for providing the data. The first author is enrolled in the ErasmusMundus joint doctorate European Graduate School in Animal Breeding and Genetics.

\section{REFERENCES}

Andersen-Ranberg, I. M., G. Klemetsdal, B. Heringstad, and T. Steine. 2005. Heritabilities, genetic correlations, and genetic change for female fertility and protein yield in Norwegian dairy cattle. J. Dairy Sci. 88:348-355.

At-Taras, E. E., and S. L. Spahr. 2001. Detection and characterization of estrus in dairy cattle with an electronic heatmount detector and an electronic activity tag. J. Dairy Sci. 84:792-798.

Aungier, S. P. M., J. F. Roche, M. Sheehy, and M. A. Crowe. 2012. Effects of management and health on the use of activity monitoring for estrus detection in dairy cows. J. Dairy Sci. 95:2452-2466.

Banos, G., S. Brotherstone, R. Thompson, J. A. Woolliams, E. Wall, and M. P. Coffey. 2004. Calculation of multiple-trait sire reliability for traits included in a dairy cattle fertility index. Anim. Sci. $79: 1-9$.

Darwash, A. O., G. E. Lamming, and J. A. Wooliams. 1997a. The phenotypic association between the interval to post-partum ovulation and traditional measures of fertility in dairy cattle. Anim. Sci. 65:9-16.

Darwash, A. O., G. E. Lamming, and J. A. Woolliams. 1997b. Estimation of genetic variation in the interval from calving to postpartum ovulation of dairy cows. J. Dairy Sci. 80:1227-1234.

de Mol, R. M., and W. E. Woldt. 2001. Application of fuzzy logic in automated cow status monitoring. J. Dairy Sci. 84:400-410.

Firk, R., E. Stamer, W. Junge, and J. Krieter. 2002. Automation of oestrus detection in dairy cows: A review. Livest. Prod. Sci. $75: 219-232$.

Hogeveen, H., C. Kamphuis, W. Steeneveld, and H. Mollenhorst. 2010. Sensors and clinical mastitis - The quest for the perfect alert. Sensors (Basel) 10:7991-8009.

Hou, Y., P. Madsen, R. Labouriau, Y. Zhang, M. S. Lund, and G. Su. 2009. Genetic analysis of days from calving to first insemination and days open in Danish Holsteins using different models and censoring scenarios. J. Dairy Sci. 92:1229-1239.

Jorjani, H. 2006. International genetic evaluation for female fertility traits. Interbull Bull. 35:42-46.

Jorjani, H. 2007. International genetic evaluation of female fertility traits in five major breeds. Interbull Bull. 37:144-147.

Löf, E., H. Gustafsson, and U. Emanuelson. 2012. Evaluation of two dairy herd reproductive performance indicators that are adjusted for voluntary waiting period. Acta Vet. Scand. 54:5.

Lopez, H., L. D. Satter, and M. C. Wiltbank. 2004. Relationship between level of milk production and estrous behavior of lactating dairy cows. Anim. Reprod. Sci. 81:209-223.

Løvendahl, P., and M. G. G. Chagunda. 2009. Short communication: Genetic variation in estrus activity traits. J. Dairy Sci. 92:46834688.

Løvendahl, P., and M. G. G. Chagunda. 2010. On the use of physical activity monitoring for estrus detection in dairy cows. J. Dairy Sci. 93:249-259.
Maatje, K., S. H. Loeffler, and B. Engel. 1997. Predicting optimal time of insemination in cows that show visual signs of estrus by estimating onset of estrus with pedometers. J. Dairy Sci. 80:1098-1105.

Madsen, P., and J. Jensen. 2010. A User's Guide to DMU. Version 6, release 5. Aarhus University, Faculty of Agricultural Sciences, Tjele, Denmark.

Miglior, F., B. L. Muir, and B. J. Van Doormaal. 2005. Selection indices in Holstein cattle of various countries. J. Dairy Sci. 88:12551263.

Petersson, K. J., B. Berglund, E. Strandberg, H. Gustafsson, A. P. F. Flint, J. A. Woolliams, and M. D. Royal. 2007. Genetic analysis of postpartum measures of luteal activity in dairy cows. J. Dairy Sci. 90:427-434.

Petersson, K. J., E. Strandberg, H. Gustafsson, and B. Berglund. 2006. Environmental effects on progesterone profile measures of dairy cow fertility. Anim. Reprod. Sci. 91:201-214.

Roelofs, J. B., F. J. C. M. van Eerdenburg, N. M. Soede, and B. Kemp. 2005. Pedometer readings for estrous detection and as predictor for time of ovulation in dairy cattle. Theriogenology 64:1690-1703.

Roxström, A., E. Strandberg, B. Berglund, U. Emanuelson, and J. Philipsson. 2001a. Genetic and environmental correlations among female fertility traits and milk production in different parities of Swedish Red and White dairy cattle. Acta Agric. Scand. A Anim. Sci. 51:7-14.

Roxström, A., E. Strandberg, B. Berglund, U. Emanuelson, and J. Philipsson. 2001b. Genetic and environmental correlations among female fertility traits, and between the ability to show oestrus and milk production in dairy cattle. Acta Agric. Scand. A Anim. Sci. 51:192-199.

Royal, M. D., A. P. F. Flint, and J. A. Woolliams. 2002a. Genetic and phenotypic relationships among endocrine and traditional fertility traits and production traits in Holstein-Friesian dairy cows. J. Dairy Sci. 85:958-967.

Royal, M. D., J. E. Pryce, J. A. Woolliams, and A. P. F. Flint. 2002b. The genetic relationship between commencement of luteal activity and calving interval, body condition score, production, and linear type traits in Holstein-Friesian dairy cattle. J. Dairy Sci. 85:3071-3080.

Royal, M. D., E. Wall, and A. P. F. Flint. 2003. The genetic relationship between interval to commencement of luteal activity postpartum and UK national fertility proofs for dairy cattle. Br. Soc. Anim. Sci. (BSAS), York, UK.

Sewalem, A., F. Miglior, G. J. Kistemaker, P. Sullivan, and B. J. Van Doormaal. 2008. Relationship between reproduction traits and functional longevity in Canadian dairy cattle. J. Dairy Sci. 91:1660-1668.

Stevenson, J. S., M. K. Schmidt, and E. P. Call. 1983. Factors affecting reproductive performance of dairy cows first inseminated after five weeks postpartum. J. Dairy Sci. 66:1148-1154.

Sun, C., P. Madsen, M. S. Lund, Y. Zhang, U. S. Nielsen, and G. Su. 2010. Improvement in genetic evaluation of female fertility in dairy cattle using multiple-trait models including milk production traits. J. Anim. Sci. 88:871-878.

Sun, C., P. Madsen, U. S. Nielsen, Y. Zhang, M. S. Lund, and G. Su. 2009. Comparison between a sire model and an animal model for genetic evaluation of fertility traits in Danish Holstein population. J. Dairy Sci. 92:4063-4071.

Veerkamp, R. F., J. K. Oldenbroek, H. J. van der Gaast, and J. H. J. van der Werf. 2000. Genetic correlation between days until start of luteal activity and milk yield, energy balance, and live weights. J. Dairy Sci. 83:577-583

Wiltbank, M., H. Lopez, R. Sartori, S. Sangsritavong, and A. Gümen. 2006. Changes in reproductive physiology of lactating dairy cows due to elevated steroid metabolism. Theriogenology 65:17-29. 